\title{
Trends in utilization of FDA expedited drug development and approval programs, 1987-2014: cohort study
}

\author{
Aaron S Kesselheim, Bo Wang, Jessica M Franklin, Jonathan J Darrow
}

Program On Regulation,

Therapeutics, And Law

(PORTAL), Division of

Pharmacoepidemiology and

Pharmacoeconomics,

Department of Medicine,

Brigham and Women's Hospital

and Harvard Medical School,

Boston 02120, MA, USA

Correspondence to:

A S Kesselheim akesselheim@ partners.org

Additional material is published online only. To view please visit the journal online (http://dx.doi. org/10.1136/bmj.h4633)

Cite this as: $B M J$ 2015;351:h4633 doi: 10.1136/bmj.h4633

Accepted: 17 August 2015

\section{ABSTRACT}

OBJECTIVE

To evaluate the use of special expedited development and review pathways at the US Food and Drug Administration over the past two decades.

DESIGN

Cohort study.

SETTING

FDA approved novel therapeutics between 1987 and 2014.

\section{POPULATION}

Publicly available sources provided each drug's year of approval, their innovativeness (first in class versus not first in class), World Health Organization Anatomic Therapeutic Classification, and which (if any) of the FDA's four primary expedited development and review programs or designations were associated with each drug: orphan drug, fast track, accelerated approval, and priority review.

\section{MAIN OUTCOME MEASURES}

Logistic regression models evaluated trends in the proportion of drugs associated with each of the four expedited development and review programs. To evaluate the number of programs associated with each approved drug over time, Poisson models were employed, with the number of programs as the dependent variable and a linear term for year of approval. The difference in trends was compared between drugs that were first in class and those that were not.

\section{WHAT IS ALREADY KNOWN ON THIS TOPIC}

The US Food and Drug Administration offers four primary pathways that can expedite the development and review of qualifying drugs

The pathways are: orphan drug designation (intended for drugs treating rare diseases), priority review (guaranteeing no more than six months of drug application review time for drugs seeming to offer a therapeutic advance over available therapy), and fast track and accelerated approval (for drugs treating serious or life threatening conditions)

The FDA's expedited development and review programs are controversial; though they have facilitated the approval of numerous transformative drugs, they also rely on early stage trials and surrogate endpoints, which produce less robust data

\section{WHAT THIS STUDY ADDS}

Over the past 20 years, there has been a statistically significant increase in the number of drugs qualifying for the FDA's expedited development and review programs, and in the number of programs for which each drug qualifies

The trend in the increased use of the FDA's expedited development and review programs is being driven by non-first in class drugs, which are less likely to be innovative or clinically transformative therapeutics

\section{RESULTS}

The FDA approved 774 drugs during the study period, with one third representing first in class agents. Priority review (43\%) was the most prevalent of the four programs, with accelerated approval ( $9 \%)$ the least common. There was a significant increase of $2.6 \%$ per year in the number of expedited review and approval programs granted to each newly approved agent (incidence rate ratio 1.026, 95\% confidence interval 1.017 to $1.035, \mathrm{P}<0.001$ ), and a $2.4 \%$ increase in the proportion of drugs associated with at least one such program (odds ratio 1.024, 95\% confidence interval 1.006 to $1.043, \mathrm{P}=0.009$ ). Driving this trend was an increase in the proportion of approved, non-first in class drugs associated with at least one program for drugs ( $\mathrm{P}=0.03$ for interaction).

\section{CONCLUSIONS}

In the past two decades, drugs newly approved by the FDA have been associated with an increasing number of expedited development or review programs. Though expedited programs should be strictly limited to drugs providing noticeable clinical advances, this trend is being driven by drugs that are not first in class and thus potentially less innovative.

\section{Introduction}

Before a new prescription drug can be sold widely in the United States, it must be approved by the US Food and Drug Administration. The FDA must determine, based on the data it receives, that the drug seems safe enough and that there is substantial evidence that the drug will have the effect it is represented to have, based on adequate and well controlled investigations such as randomized controlled trials assessing validated clinical outcomes. The FDA makes these determinations by reviewing results from experimental clinical trials conducted by or on behalf of the drug's manufacturer, usually divided into three phases: phase 1 trials in a small number (generally 20-80) of often healthy participants to identify the drug's pharmacokinetics; ${ }^{1}$ phase 2 studies in somewhat larger numbers of patients (no more than several hundred) with the disease or condition under study; ${ }^{2}$ and phase 3 trials in hundreds or thousands of patients to generate safety and efficacy data sufficient to evaluate the overall benefit-risk relation of the drug. ${ }^{3}$ The FDA must then review the data, and currently has a 10 month window in which to make its approval decision. While this multistage drug development and regulatory review process screens out many unsafe or ineffective experimental drugs, it also delays widespread access to those drugs ultimately shown to be safe and effective, which may be problematic for patients with serious or life threatening conditions who have no other treatment options. 
In response, regulators and legislators created four programs-one pathway and three designations-to expedite approval of promising new drugs intended for unmet medical need (table 1). ${ }^{4}$ In 1983, the US Congress passed the Orphan Drug Act, which created special tax breaks and market exclusivity periods for products that are intended to treat patients with diseases potentially too rare for large randomized trials and for which the market may not provide adequate incentives for investment. ${ }^{5}$ Though an orphan drug designation does not formally change the statutory approval standard, studies show that orphan drugs are often approved on the basis of clinical trials that would be insufficient for traditional non-orphan products, such as small, non-randomized, unblinded, single arm trials. ${ }^{6}$ In 1988, the FDA formalized the "fast track" designation, which permitted approval of drugs treating life threatening or severely debilitating diseases after a single phase 2 study. ${ }^{7}$ In 1992, Congress authorized the "accelerated approval" pathway, allowing drugs treating serious or life threatening illnesses to be approved on the basis of surrogate endpoints reasonably likely to predict patient benefit. ${ }^{8}$ Surrogate endpoints consist of markers such as laboratory measurements or radiographic images, and contrast with clinical endpoints such as reduction in patient symptoms or mortality. ${ }^{8}$ In 1992, the FDA also made official a priority review designation, the predecessor to which was established in 1975, ${ }^{9}$ that guaranteed FDA review of new drug applications within six months of submission for drugs seeming to offer a therapeutic advance over available therapy. ${ }^{10}$

Studies have suggested that these programs reduce development and review times; for example, in one sample of anticancer drugs, there was a trend towards a shorter clinical trial period (median 5.1 years for orphan (interquartile range 4.5-7.0) $v 6.9$ years for non-orphan drugs (6.5-8.0)), ${ }^{8}$ whereas the US Government Accountability Office reports that the FDA acts on $90 \%$ of all priority review drugs within six months. ${ }^{11}$ In addition,

\begin{tabular}{|c|c|c|c|c|}
\hline $\begin{array}{l}\text { Program } \\
\text { name }\end{array}$ & $\begin{array}{l}\text { Year } \\
\text { instituted }\end{array}$ & $\begin{array}{l}\text { Characteristics of } \\
\text { qualifying products }\end{array}$ & $\begin{array}{l}\text { Does it formally } \\
\text { change evidentiary } \\
\text { standard? }\end{array}$ & $\begin{array}{l}\text { Phase during } \\
\text { which it exerts } \\
\text { most direct effect }\end{array}$ \\
\hline Orphan drug & 1983 & $\begin{array}{l}\text { Treats disease occurring in } \\
<200000 \text { people per year } \\
\text { in United States }\end{array}$ & No & Drug development \\
\hline Fast track & 1988 & $\begin{array}{l}\text { Treats life threatening or } \\
\text { severely debilitating } \\
\text { diseases }\end{array}$ & $\begin{array}{l}\text { Yes; can approve } \\
\text { after single phase } 2 \\
\text { study }\end{array}$ & $\begin{array}{l}\text { Drug development } \\
\text { and FDA review }\end{array}$ \\
\hline $\begin{array}{l}\text { Priority } \\
\text { review }\end{array}$ & 1992 & $\begin{array}{l}\text { Seems to offer therapeutic } \\
\text { advance over available } \\
\text { therapy }\end{array}$ & No & FDA review \\
\hline $\begin{array}{l}\text { Accelerated } \\
\text { approval }\end{array}$ & 1992 & $\begin{array}{l}\text { Treats serious or life } \\
\text { threatening illnesses }\end{array}$ & $\begin{array}{l}\text { Yes; can approve on } \\
\text { basis of surrogate } \\
\text { endpoint reasonably } \\
\text { likely to predict } \\
\text { patient benefit }\end{array}$ & $\begin{array}{l}\text { Drug development } \\
\text { and FDA review }\end{array}$ \\
\hline $\begin{array}{l}\text { Breakthrough } \\
\text { therapy }\end{array}$ & 2012 & $\begin{array}{l}\text { Treats serious disease for } \\
\text { which preliminary clinical } \\
\text { evidence suggests } \\
\text { substantial improvement } \\
\text { over existing therapies on } \\
\text { one or more clinically } \\
\text { important endpoints }\end{array}$ & No & $\begin{array}{l}\text { Drug development } \\
\text { and FDA review }\end{array}$ \\
\hline
\end{tabular}

numerous transformative drugs have emerged from these designations. ${ }^{12}$ The first tyrosine kinase inhibiting drug, imatinib (Gleevec; Novartis, Basel, Switzerland), benefited from all four programs, leading to approval for chronic myelogenous leukemia after only 2.5 months of FDA review. However, these programs have also been a source of controversy. Approving drugs on the basis of surrogate endpoints, for example, can be risky, since promising surrogates may later be found not to accurately predict actual changes in patient health outcomes. ${ }^{13}$ For example, gemtuzumab (Mylotarg; Pfizer, New York City, NY) benefited from all four programs leading to its approval in 2000 for acute myeloid leukemia based on surrogate endpoints. ${ }^{14}$ In 2010, the drug was removed from the market after confirmatory studies contradicted the initial studies, demonstrating no efficacy and increased mortality. ${ }^{15}$ Studies have also found increased safety issues in the post-marketing phase for drugs benefiting from expedited approval, including adverse events and boxed warnings for agents receiving shorter review times. ${ }^{16-18}$

Given the widely recognized risks to public health inherent in approving prescription drugs for widespread use on the basis of limited data, the FDA's expedited drug development and approval programs were intended to be limited in scope, applying only to investigational agents offering the greatest promise of therapeutic advance to patients with no other reasonable therapeutic choices. ${ }^{8} 19$ However, a growing number of new molecular entities has been associated with these programs; in 2013, 15 (56\%) of the 27 new drugs benefited from at least one such program, with 12 $(80 \%)$ of these benefiting from multiple programs..$^{20}$ We have previously collected a database of all new molecular entities and original therapeutic biologics approved by the FDA between 1987 and 2013. ${ }^{21}$ Using those data (updated through 2014), we sought to analyze trends in the FDA's utilization of its expedited drug development and review programs and to determine whether the recent expansion in the number of products approved using these programs is related to the FDA's review of more truly innovative drugs.

\section{Methods}

\section{Study drugs}

We have previously described how we collected our study sample of novel therapeutics between 1987 and 2014.22 Briefly, we scoured the Drugs@FDA monthly drug approval reports database (including original new drug approvals and biologic license application approvals) and the FDA's annual reports summarizing new molecular entities and new biologics spanning 1999 to 2014. We used historical sources, including published articles as well as the Federal Register, to identify drugs approved but later withdrawn during this period. Some drugs categorized by the FDA as new molecular entities were associated with the same generic name (for example, hyaluronidase is the generic name for both Amphadase (Amphastar, Rancho Cucamonga, CA) and Vitrase (Bausch and Lomb, Tampa, FL). In these cases, the convention of the FDA was followed and each drug 
was treated as a distinct new molecular entity. In other cases, new biologic license application approvals were not characterized by the FDA as new molecular entities. For example, a biologic license application for streptokinase (Streptase, CSL Behring Canada, Ottawa, Ontario, Canada) was approved in 1997, but streptokinase had been "widely employed" 22 for decades; in this case also, the convention of the FDA was followed and streptokinase was not included as a new molecular entity. Vaccines and diagnostics were not included in this study.

From this list of drugs we extracted their year of approval and then categorized their innovativeness as either first in class (first agent approved within its respective drug class) or not first in class, using a framework previously published by FDA scientists. ${ }^{23}$ Next, we used the World Health Organization's Anatomic Therapeutic Classification (ATC) system as our framework to classify each drug into one of 13 different therapeutic categories: allergy and pulmonology; cardiovascular disease and its risk factors, including diabetes mellitus, hyperlipidemia, and hypertension; dermatology; endocrinology; gastroenterology; genitourinary disease; hematology; infectious disease; musculoskeletal disease and immunomodulators; neuropsychiatry; oncology; ophthalmology; and all other therapeutic areas. ${ }^{24}$ In the cases of drugs associated with multiple ATC codes, we examined the earliest available approval documents and other data sources to determine which code most closely corresponded to the indication associated with the initial US approval. For the approximately $6 \%$ of drugs in the database not listed in the WHO ATC database, the authors assigned a primary ATC code by consensus.

Finally, we also determined which of the four primary expedited development and review programs were associated with each drug: orphan, fast track, accelerated approval, and priority review (we did not study the breakthrough therapy designation because of its recent implementation ${ }^{6}$ ). All four programs are intended to encourage the development and speed the evaluation of innovative products to meet serious unmet health needs. A product may qualify for more than one such program. Drugs were categorized as priority review using the FDA's annual priority approval reports, the Drugs@FDA database, and information provided by the FDA under the Freedom of Information Act. Though the two tiered priority review classification system was formalized by Congress in 1992, a previous three tiered classification system grouped drugs into types A (important therapeutic gain), B (modest therapeutic gain), and $\mathrm{C}$ (little or no therapeutic gain). ${ }^{25}$ For drugs approved between 1987 and 1992, types A and B were considered to correspond to priority review and type $C$ to standard review. Drugs were categorized as subpart $\mathrm{E}$ or fast track drugs using an FDA document entitled "CDER fast track products approved since 1998 through June 1, 2010,"26 the FDA's annual new drugs summaries, a law review article, ${ }^{27}$ and information provided by the FDA under the Freedom of Information Act. Drugs were categorized as benefitting from accelerated approval using FDA documents including "accelerated and restricted approvals under subpart $\mathrm{H}$ (drugs) and subpart E (biologics)," 28 "CDER drug and biologic accelerated approvals as of September 30, 2011,"29 and the FDA's annual new drugs summaries. Drugs were categorized as orphan drugs using the FDA's monthly drug approval reports database and the FDA's orphan drug list. ${ }^{30} \mathrm{~A}$ few drugs not listed as orphan drugs in the Drugs@FDA monthly approval reports were listed as having received an orphan designation in the FDA's orphan drug list; the orphan drug list was considered to be more authoritative if the difference could not otherwise be explained.

\section{Statistical analysis}

We first descriptively analyzed the association between therapeutic class and designation under expedited programs, calculating the proportion of drugs in each therapeutic class associated with each program. We then fit a series of logistic regression models to evaluate trends in the proportion of drugs associated with each regulatory program. The dependent variable in each model was a binary indicator of whether a given drug was associated with at least one expedited development or FDA review program (yes or no). In the first model we included data on all drugs and modeled the trend associated with at least one of the four possible programs using a linear term for the year of drug approval. In the second logistic regression model, we assessed the difference in trends of being associated with at least one early access program between drugs that were first in class compared with those that were not.

To evaluate the number of programs associated with each approved drug over time, we also estimated Poisson models with the number of programs as the dependent variable and a linear term for year of approval. Poisson models were conducted to analyze trends in the mean number of expedited programs associated with all drugs and the difference in trends in the mean number of all expedited programs associated with first in class versus non-first in class therapeutics. We examined the same trends excluding the orphan drug designation, as a sensitivity analysis.

\section{Patient involvement}

No patients were involved in setting the research question or the outcome measures, nor were they involved in recruitment or the design and implementation of the study. There are no plans to involve patients in dissemination.

\section{Results}

\section{Study sample}

From 1987 through 2014, the FDA approved 774 drugs meeting our inclusion criteria, ranging from 17 approvals in 1988 to 53 in 1996 (table 2). The most common therapeutic areas were infectious disease $(n=109,14 \%)$, oncology ( $n=107,14 \%)$, cardiovascular disease and its risk factors $(n=99,13 \%)$, and neuropsychiatry $(n=97$, $13 \%)$. First in class agents comprised one third of the 


\begin{tabular}{|c|c|}
\hline Characteristics & No $(\%) *$ \\
\hline \multicolumn{2}{|l|}{ Therapeutic area: } \\
\hline Infectious disease & $109(14)$ \\
\hline Oncology & $107(14)$ \\
\hline Cardiovascular disease and its risk factorst & 99 (13) \\
\hline Neuropsychiatry & $97(13)$ \\
\hline Musculoskeletal disease and immunomodulators & $80(10)$ \\
\hline Gastroenterology & $58(7)$ \\
\hline Hematology & $43(6)$ \\
\hline Allergy and pulmonology & $35(5)$ \\
\hline Ophthalmology & $34(4)$ \\
\hline Dermatology & $31(4)$ \\
\hline Endocrinology & $25(3)$ \\
\hline Genitourinary disease & $19(2)$ \\
\hline Other & $37(5)$ \\
\hline \multicolumn{2}{|l|}{ Expedited programs: } \\
\hline Orphan drug & $195(25)$ \\
\hline Fast track & $144(19)$ \\
\hline Accelerated approval & $68(9)$ \\
\hline Priority review & $331(43)$ \\
\hline \multicolumn{2}{|l|}{ Innovativeness $\ddagger$} \\
\hline First in class drug & $252(33)$ \\
\hline Non-first in class drug & $508(67)$ \\
\hline
\end{tabular}

drugs for which FDA classification data were available (33\%, 252/760).

Across nearly all therapeutic classes, priority review was the most common of the four programs in our study, whereas accelerated approval was least common (fig 1). Oncology was the most prevalent therapeutic category

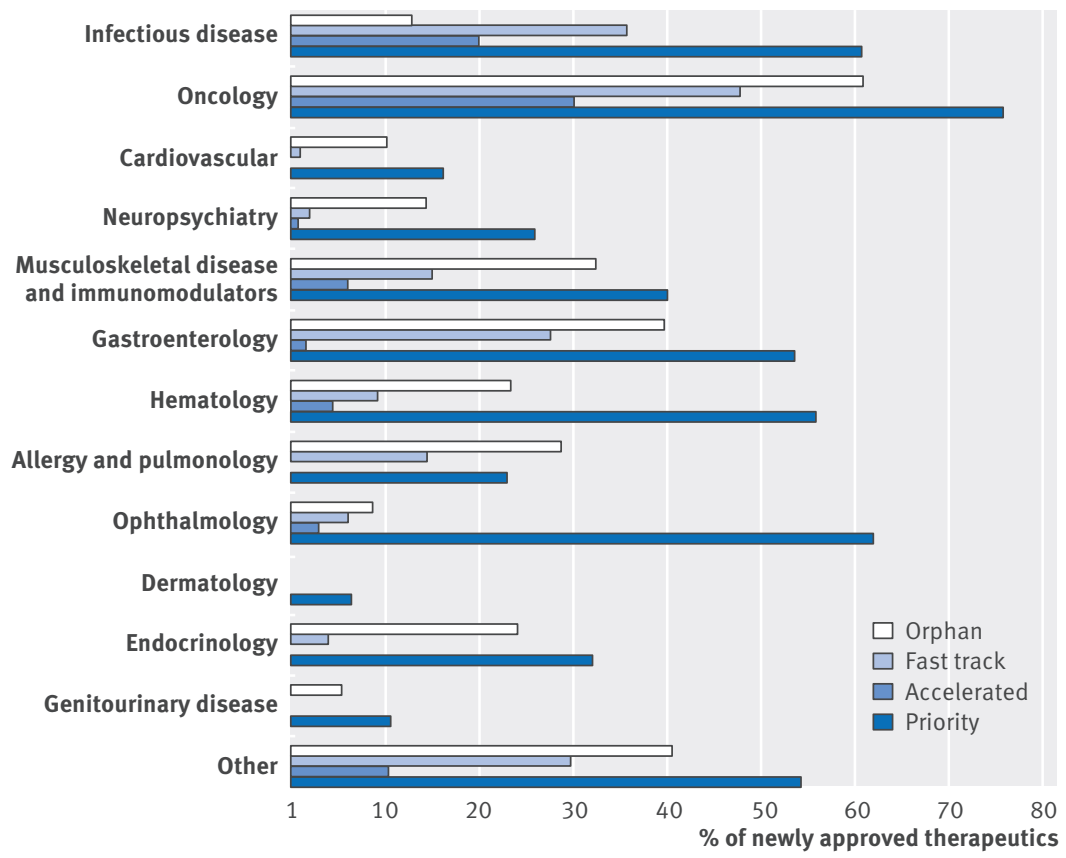

Fig 1 | Expedited designations granted to therapeutics approved US Food and Drug Administration in each therapeutic category. Proportion of newly approved therapeutics from 1987-2014 that were associated with at least one of four FDA expedited programs (orphan, accelerated approval, fast track, priority review), divided by therapeutic area for all four programs-priority review $(76 \%, 81 / 107)$, orphan drug (61\%, 65/107), fast track (48\%, 51/107), and accelerated approval (30\%, 32/107). By contrast, few dermatology agents participated in any program, with only $6 \%(2 / 31)$ being granted priority review and none being associated with the orphan drug, fast track, or accelerated approval programs. Participation rates in the different expedited programs were not always correlated. Though $62 \%$ of ophthalmology agents (21/34) received priority review, few were approved through the orphan drug $(9 \%, 3 / 34)$, fast track $(6 \%, 2 / 34)$, or accelerated approval $(3 \%, 1 / 34)$ programs.

\section{Trends in expedited development and FDA review programs}

Drugs could qualify for more than one program, and the average number of expedited development and review programs granted to each newly approved agent varied from a low of 0.53 in 1987 to a high of 1.72 in 2014 (see supplementary appendix for yearly data). During the entire study period, we observed a significant increase in trend of $2.6 \%$ per year (incidence rate ratio 1.026, 95\% confidence interval 1.017 to 1.035), $\mathrm{P}<0.001$ ) (fig 2). We also observed a $2.4 \%$ increase in the proportion of drugs associated with at least one program (odds ratio 1.024, $95 \%$ confidence interval 1.006 to $1.043, \mathrm{P}=0.009$ ), peaking at 75\% (15/20) in 2005. The results were consistent when the orphan drug designation was excluded, with a $2.5 \%$ increase in the number of programs for each drug (incidence rate ratio 1.025, 95\% confidence interval 1.014 to 1.036 ) and $2.3 \%$ increase in the proportion of drugs associated with at least one program (1.023, 1.005 to 1.042 ).

When we considered first in class and non-first in class drugs separately (fig 3), we found that the average number of expedited development and review programs assigned for each first in class drug reached a maximum of 2.25 programs in 2011 and 1.91 for each non-first in class drug in 2005 ( $\mathrm{P}=0.16$ for interaction). However, an increase in the proportion of approved drugs associated with at least one program was observed only for drugs that were not first in class $(\mathrm{P}=0.03$ for interaction).

\section{Discussion}

We found that in the past two decades, newly approved drugs have been associated with an increasing number of expedited development or Food and Drug Administration review programs and that these programs have expanded to include a larger proportion of products approved overall. Though some drugs associated with an expedited program may indeed provide noticeable clinical advances, this trend is being driven by drugs that are not first in class and thus potentially less innovative.

These data have important implications for patient care. Special regulatory designations allow drugs to be approved at earlier stages based on less rigorous clinical testing; for example, one review showed drugs with orphan designations or granted accelerated approval are also more likely than drugs without these designa- 


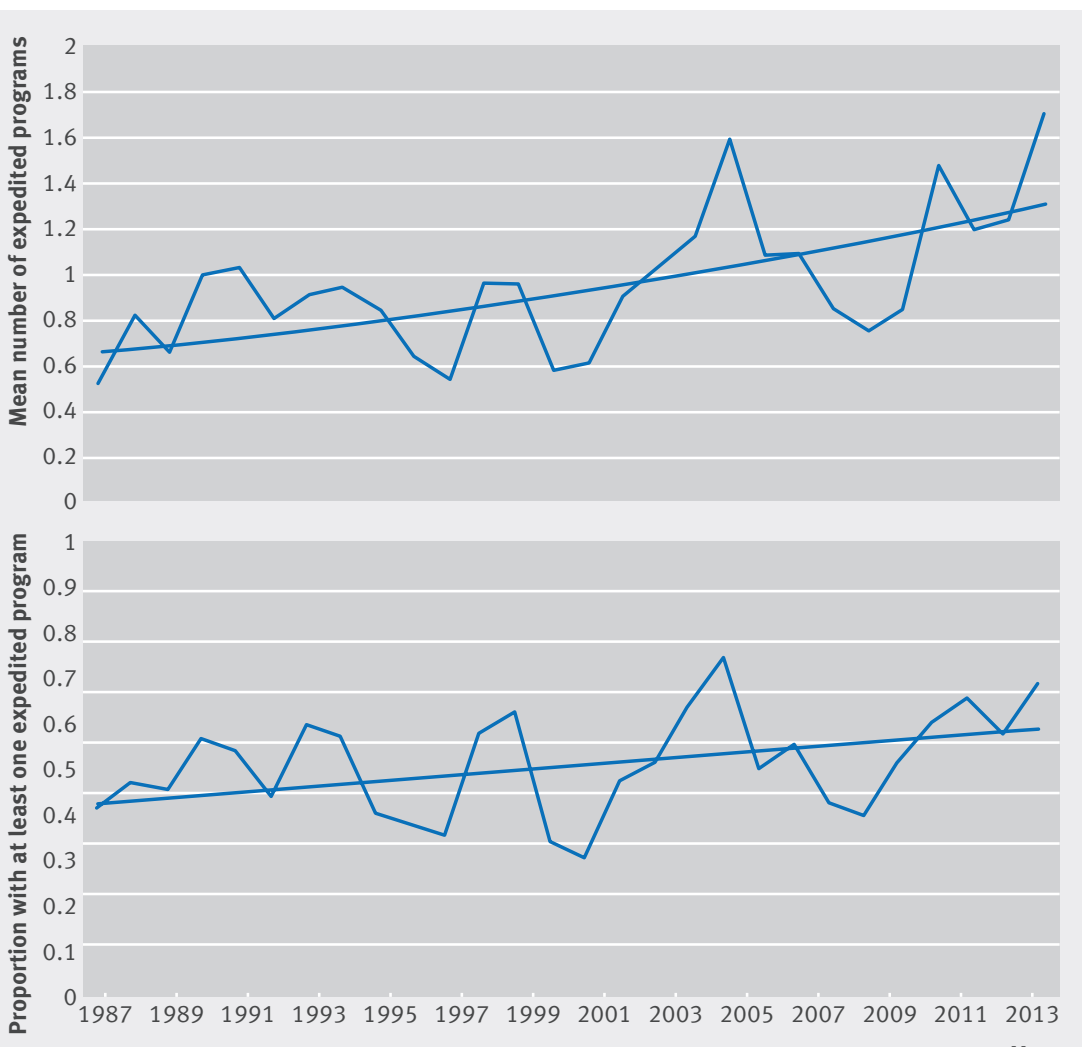

Fig 2 | Time trend analyses of all expedited programs associated with therapeutics approved by US Food and Drug Administration, 1987-2014. Top: mean number of expedited development and FDA review programs (orphan, accelerated approval, fast track, and priority review) granted to each newly approved prescription drug from 1987-2014. Drugs can be associated with more than one program. Bottom: proportion of newly approved prescription drugs from 1987-2014 that were associated with at least one of the four programs
Much information can be learnt about drug effectiveness and safety after a drug is approved, particularly through prospective trials and well controlled observational studies. Provisional evidence leading to a drug's approval may later be validated; for example, one FDA review showed that most anticancer drugs approved using the accelerated approval pathway are eventually confirmed as safe and effective on the basis of successful post-approval studies. ${ }^{33}$ However, post-approval studies requested by the FDA may be delayed or sometimes not completed at all. ${ }^{34}$ In light of the growing proportion of drugs associated with expedited programs, it is increasingly important for patients that post-marketing commitments are honored in a timely manner, which may require granting the FDA strengthened statutory authority to impose fines on tardy manufacturers (such fines are difficult to impose in practice and have never been invoked) or, in extreme cases, to temporarily suspend approval until the requested studies are completed.

Expedited development and FDA review programs are generally intended for drugs treating serious or life threatening conditions that address unmet medical needs. In evaluating the hypothesis that more drugs intended to treat such conditions are being approved over time, we observed that a greater proportion of programs were being applied to drugs that were not the first members of their classes. Such drugs are more likely to be only incrementally innovative and may not represent a clinical advance. Though incremental innovation can be important, new drug classes are more likely to represent transformational advances in patient care. Another study of drug approvals in Canada similarly found only a fair correlation between an expedited review designation and a drug's therapeutic value. ${ }^{35}$

Less innovative products moving through the FDA's expedited development and review programs can divert limited governmental resources. Our results suggest that the inclusion criteria for these pathways are expanding over time to include less serious conditions. For example, bimatoprost (Latisse; Allergan, Coolock, Dublin, Ireland) was granted priority review when it was first approved in 2008 for hypotrichosis of the eyelids, a clearly less serious condition. ${ }^{36}$ In addition, the increasing complexity of the expedited approval regulatory framework may itself require substantial resources, both of the FDA in developing, explaining, and administering these programs, and of industry in strategically considering and applying for them and in complying with their requirements.

One reason why drugs receive more than one designation is that though each designation is intended to expedite drug development and review, each has slightly different regulatory implications. Designations also can be granted by different entities within the agency at different times. In particular, orphan drug designation is determined by the Office of Orphan Products Development, whereas fast track and priority review are assigned by the group responsible for drug review. Fast track is usually assigned early in development, whereas priority review may be requested along with submission of a full application. ${ }^{37}$ 

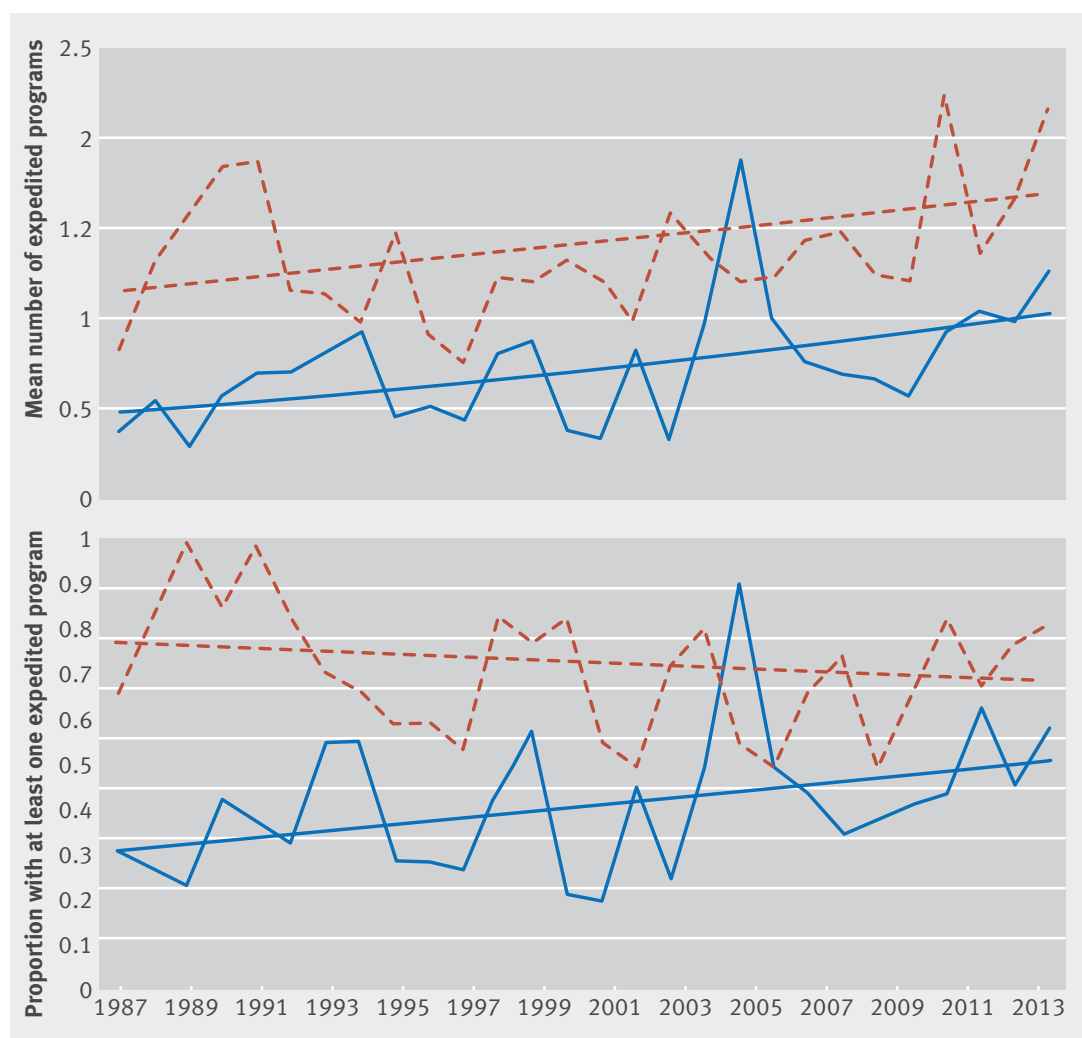

Year

Fig 3 Time trend analyses comparing all expedited programs associated with first in class and follow-on therapeutics approved by US Food and Drug Administration, 1987-2014. Top: mean number of expedited development and FDA review programs (orphan, accelerated approval, fast track, and priority review) granted to each newly approved first in class (red dotted line) and non-first in class (blue solid line) prescription drug from 1987-2014. Drugs can be associated with more than one program. Bottom: proportion of newly approved first in class (red dotted line) and non-first in class (blue solid line) prescription drugs from 1987-2014 that were granted at least one of the four programs

Policy implications

Despite the growing application of expedited development and FDA review programs to new drugs, Congress continues to authorize more such pathways. In 2012, as part of the FDA Safety and Innovation Act, which re-authorized prescription drug user fees that pharmaceutical manufacturers pay to FDA to support its budget, legislators created the Breakthrough Therapy designation, ${ }^{38}$ which was intended to provide certain highly promising drugs with more internal FDA resources and attention to ensure that their development was given enhanced attention by regulators (it did not formally alter the approval standard). Mirroring the pattern of program expansions we observed in our study, the FDA received nearly 250 applications for breakthrough therapy status in the first two years, of which it granted $68,{ }^{39}$ even though its sponsoring legislators intended it to apply to only a handful of drugs each year ${ }^{40}$ and the FDA predicted that two to four drug candidates each year would be granted breakthrough drug designation. ${ }^{41}$ Among these 68,12 have since been approved by the FDA, including four treatments for chronic lymphocytic leukemia. It is doubtful that a single disease condition can be the subject of four true "breakthroughs" in such a short time frame. Although the creation of the breakthrough therapy designation coincided with a statutory increase in user fees (substantial increases in user fees have occurred at each renewal of the original 1992 user fee legislation), the 2012 statutory amendments did not specifically allocate any resources to administering the growing breakthrough therapy program, despite the substantial resources that it now requires. The 21st Century Cures Act, which recently was approved by the US House of Representatives, would create an even further expedited pathway for new antibiotics and antifungals, which would permit their approval without conventional clinical trials. ${ }^{42}$

\section{Limitations of this study}

Our study has certain limitations; in particular, in examining trends in the application of the expedited development and FDA review programs, we did not investigate individual outcomes from the drugs in our sample. Therefore, we do not claim that the programs were improperly utilized in any specific case, or that FDA approval of any particular drug was not justified. In addition, the programs we analyzed have some varying characteristics; for example, accelerated approval and fast track formally change the nature of the evidence considered sufficient for approval, whereas the orphan drug and priority review designations do not. However, all four programs share a common thread of emphasizing speed and efficiency during drug development and FDA review. Finally, some of the programs are correlated, for example, in that a drug granted accelerated approval designation is more likely to receive priority review status. In a sensitivity analysis, we excluded the orphan drug designation from the analysis, and the trends we identified did not change.

\section{Conclusions}

In this review of FDA drug approvals we found an increasing prevalence of expedited development and review programs that cannot be attributed to an increase in the number of innovative new drug classes over time. Though these programs were designed as exceptions to the standard drug development and FDA approval process for drugs addressing unmet needs associated with serious or life threatening diseases, by the end of our study period, a majority of newly approved drugs were associated with at least one of these special programs, meaning that the exceptions had become more common than the rule.

Contributors: ASK and JJD conceived the study. All authors analysed and interpreted the data. ASK and BW drafted the manuscript. ASK, BW, JMF, and JJD revised the manuscript and all authors approved the final version. ASK is the guarantor of the study. All authors had full access to all of the data (including statistical reports and tables) in the study and can take responsibility for the integrity of the data and the accuracy of the data analysis.

Funding: This investigator initiated study was not funded by industry. ASK's work is supported by the Greenwall Faculty Scholars Program in Bioethics and the Harvard Program in Therapeutic Science. The funders had no role in the conception, writing, or review of the manuscript.

Competing interests: All authors have completed the ICMJE uniform disclosure form at www.icmje.org/coi disclosure.pdf and declare: no support from any organisation for the submitted work; no financial 
relationships with any organisations that might have an interest in the submitted work in the previous three years; no other relationships or activities that could appear to have influenced the submitted work. Ethical approval: Not required as this study was based on publicly available data and involved no individual patient data collection or analysis.

Data sharing: No additional data available.

Transparency: The lead author (ASK) affirms that the manuscript is an honest, accurate, and transparent account of the study being reported; that no important aspects of the study have been omitted; and that any discrepancies from the study as planned (and, if relevant, registered) have been explained.

This is an Open Access article distributed in accordance with the Creative Commons Attribution Non Commercial (CC BY-NC 4.0) license, which permits others to distribute, remix, adapt, build upon this work non-commercially, and license their derivative works on different terms, provided the original work is properly cited and the use is noncommercial. See: http://creativecommons.org/licenses/by-nc/4.0/.

1 Food and Drug Administration. Phases of an investigation: phase 1. 21 CFR § 312.21(a). FDA, 2014

2 Food and Drug Administration. Phases of an investigation: phase 2. 21 CFR § 312.21(b). FDA, 2014.

3 Food and Drug Administration. Phases of an investigation: phase 3. 21 CFR § 312.21(c). FDA, 2014.

4 Darrow IJ, Avorn J, Kesselheim AS. New FDA breakthrough-drug category-implications for patients. N Engl J Med 2014;370:1252-8.

5 Designation of Drugs for Rare Diseases or Conditions, 21 U.S.C. § 360bb(a)(2) (2008).

6 Kesselheim AS, Myers JA, Avorn J. Characteristics of clinical trials to support approval of orphan vs nonorphan drugs for cancer. JAMA 2011;305:2320-26.

7 Food and Drug Administration, DHHS. Investigational new drug antibiotic, and biological drug product regulations: procedures for drugs intended to treat life-threatening and severely debilitating illnesses. Fed Regist 1988;53:41516.

8 Food and Drug Administration, DHHS. New drug, antibiotic, and biological drug product regulations; accelerated approval. Fed Regist 1992;57:58942-60.

9 Halperin JA. From investigation to marketplace: moving drugs through the system. Food Drug Cosmet Law J 1981;36:166-74

10 Prescription Drug User Fee Act of 1992. 138 Cong Rec H9095, 1992.

11 Government Accountability Office. FDA has met most performance goals for reviewing applications. Mar 2012. www.gao.gov/ assets/590/589762.pdf

12 Kesselheim AS, Tan YT, Avorn J. The roles of academia, rare diseases, and repurposing in the development of the most transformative drugs. Health Aff (Millwood) 2015;34:286-94

13 Svensson S, Menkes DB, Lexchin J. Surrogate outcomes in clinical trials: a cautionary tale. JAMA Intern Med 2013;173:611-2.

14 Temple R. Mylotarg (gemtuzumab ozogamicin) approval letter (NDA 21-174). 2000. www.accessdata.fda.gov/drugsatfda_docs/ appletter/2000/21174ltr.pdf

15 Food and Drug Administration. Mylotarg (gemtuzumab ozogamicin): market withdrawal. FDA, Jun 21, 2010. www.fda.gov/Safety/ MedWatch/SafetyInformation/SafetyAlertsforHumanMedical Products/ucm 216458.htm.

16 Carpenter D, Zucker EJ, Avorn J. Drug-review deadlines and safety problems. N Engl J Med 2008;358:1354-61.

17 Lexchin J. New drugs and safety: what happened to new active substances approved in Canada between 1995 and 2010? Arch Intern Med 2012;172:1680-1

18 Olson MK. The risk we bear: the effects of review speed and industry user fees on new drug safety. J Health Econ 2008;27:175-200.

19 Nelson RJ. Regulation of investigational new drugs: "giant step for the sick and dying"? Georgetown Law J 1988;77:463-84.

20 Sanger-Katz M. Speedy drug approvals have become the rule, not the exception. NY Times 2015 May 1. www.nytimes.com/2015/05/02/ upshot/speedy-drug-approvals-have-become-the-rule-not-theexception.html?_r=0\&abt=0002\&abg=0.
21 Darrow JJ, Kesselheim AS. Drug development and FDA approval, 1938-2013. N Engl J Med 2014;370:e39.

22 Food and Drug Administration, DHHS. Biological products; bacterial vaccines and toxoids; implementation of efficacy review. Fed Regist 1985;240: 51002-117.

23 Lanthier M, Miller KL, Nardinelli C, et al. An improved approach to measuring drug innovation finds steady rates of first-inclass pharmaceuticals, 1987-2011. Health Aff (Millwood) 2013;32: 1433-9.

24 World Health Organization Collaborating Center for Drug Statistics Methodology.www.whocc.no/atc_ddd_index/.2013.

25 Crawford S. Changes in FDA drugclassification and priority review policy. Am J Hosp Pharm 1992;49:2383-6.

26 Food and Drug Administration, DHHS. CDER fast track products approved since 1998 through June 1, 2010. www.fda.gov/downloads/ Drugs/UCM216527.pdf.

27 Shulman SR, Brown JS. The Food and Drug Administration's early access and fast track approval initiatives: how have they worked? Food Drug Law J 1995;50:503-31.

28 Food and Drug Administration, DHHS. Accelerated and restricted approvals under Subpart H (drugs and Subpart E (biologics). 2014 www.fda.gov/Drugs/DevelopmentApprovalProcess/HowDrugsare DevelopedandApproved/DrugandBiologicApprovalReports/ ucm121597.htm.

29 Food and Drug Administration, DHHS. CDER drug and biologic accelerated approvals as of September 30, 2011. www.fda.gov/ downloads/Drugs/DevelopmentApprovalProcess/How DrugsareDevelopedandApproved/DrugandBiologicApprovalReports/ UCM278506.pdf.

30 Food and Drug Administration, DHHS. 2015. Search orphan drug designations and approvals. www.accessdata.fda.gov/scripts/ opdlisting/oopd/.

31 Light DW, Lexchin J. Why do cancer drugs get such an easy ride? BMJ 2015;350:h2068.

32 Prasad V, Mailankody S. The accelerated approval of oncologic drugs: lessons from ponatinib. JAMA 2014;311:353-4

33 Johnson JR, Ning YM, Farrell A, Justice R, Keegan P, Pazdur R. Accelerated approval of oncology products: the food and drug administration experience. J Natl Cancer Inst 2011;103:636-44

34 Fain K, Daubresse M, Alexander GC. The Food and Drug Administration Amendments Act and postmarketing commitments. IAMA 2013;310:202-4

35 Lexchin J. Health Canada's use of its priority review process for new drugs: a cohort study. BMJ Open 2015;5:e006816

36 Food and Drug Administration, DHHS. Drugs@FDA. www.accessdata. fda.gov/scripts/cder/drugsatfda/index.cfm?fuseaction=Search. DrugDetails.

37 Food and Drug Administration, DHHS. Expedited programs for serious conditions-drugs and biologics. May 2014. www.fda.gov/ downloads/drugs/guidancecomplianceregulatoryinformation/ guidances/ucm358301.pdf

38 Food and Drug Administration Safety and Innovation Act. Pub L No 112-144. §902, 126 Stat 993, 2012.

39 Kesselheim AS, Darrow JJ. FDA designations for therapeutics and their impact on drug development and regulatory review outcomes. Clin Pharmacol Ther 2015;97:29-36.

40 McCrimmon KK. 'Breakthrough' drugs speed paths to cures and the NBA. Health News Colorado 2013 May 15. www.healthnewscolorado. org/2013/05/15/breakthrough-drugs-speed-path-to-curesand-the-nba/.

41 Health Policy Brief: breakthrough therapy designation. Health Aff (Millwood) May 15, 2014

42 Avorn J, Kesselheim AS. The 21st Century Cures Act-will it take us back in time. N Engl J Med 2015;372:2473-5.

(c) BMJ Publishing Group Ltd 2015

Web extra appendix table: expedited programs associated with therapeutics approved by FDA, 1987-2014 